\title{
Personalized and Dynamic Therapy for Breast Cancer: A Preclinical Perspective
}

\author{
Huanrong $\operatorname{Lan}^{1}$, Jianfen $\mathrm{Gu}^{2}$, Haidi $\mathrm{Li}^{2}$, Ketao Jin ${ }^{2}$
}

Corresponding author:

Ketao Jin, MD

Department of Gastrointestinal Surgery

Shaoxing People's Hospital

Shaoxing Hospital of Zhejiang University

No. 568, Zhongxing North Road

Shaoxing, 312000, Zhejiang Province

P. R. China

E-mail: jinketao2001@zju.edu.cn
'Department of Breast and Thyroid Surgery, Shaoxing People's Hospital

Shaoxing Hospital of Zhejiang University, P. R. China

'Department of Gastrointestinal Surgery, Shaoxing People's Hospital

Shaoxing Hospital of Zhejiang University, P. R. China

\section{ABSTRACT}

Breast cancer is one of the leading causes of mortality worldwide. Genomic studies have provided key insights into how breast cancer develop, evolve, metastasize, recurrence and respond to treatment. The advance of next-generation sequencing (NGS) and bioinformatics has led to an unprecedented view of the breast cancer genome and its evolution, and made the dynamic monitoring of recurrence and selective evolution of breast cancer during therapy a reality. Here we illustrate a proposed preclinical strategy of personalized and dynamic therapy for breast cancer based on the technologies of NGS and patient-derived tumor xenograft (PDX) model. The goal of this strategy is to provide a preclinical model of personalized and dynamic therapy for breast cancer to improve patients' outcomes.

Key words: breast cancer, next-generation sequencing, personalized cancer therapy, dynamic therapy

\section{INTRODUCTION}

The breast cancer is the leading cause of cancer death in women with approximately 521,900 deaths per year worldwide (1). It is predicted that there will be about 4292,000 newly diagnosed invasive cancer cases in 2015 in China (2). The most commonly diagnosed cancer among women is breast cancer. It is expected to account for $15 \%$ of all new cancers in women (2).

The patient-derived tumor xenograft (PDX) model retains similar growth and histopathological and molecular features compared with the original cancers. The unique feature of PDX models is that the implanted tumor tissue still retains most of its normal architecture and function $(3,4)$. These characteristics make a PDX model an ideal method to predict tumor response to anticancer therapy including breast cancer (4-6) as well as to facilitate personalized cancer therapy.

Recent advances in genomics technologies are now providing new opportunities for the analysis of tumor DNA. Next-generation sequencing (NGS) tech- 
nologies are now being applied to tumor DNA analysis to allow more comprehensive detection of mutations across wider genomic regions. Advances in NGS have made it possible to precisely characterize all somatic coding mutations that occur during the development and progression of individual cancers. The application of NGS together with advanced computational methods has provided technical support in selecting and monitoring therapy for breast cancer.

In this article, we illustrate a proposed preclinical strategy of personalized and dynamic therapy for breast cancer based on the technologies of PDX model and NGS to provide a preclinical model of personalized and dynamic therapy for breast cancer for improvement of patients' outcomes.

\section{SELECTIVE EVOLUTION DURING CANCER THERAPY}

Cancer is a disease characterized by Darwinian evolution $(7,8)$. Clones evolve dynamically in space and time underpinning important emergent features such as metastasis, drug resistance and recurrence (9-15). Advances in NGS and bioinformatics have led to an unprecedented view of the cancer genome and its evolution. An overwhelming body of evidence has been collected demonstrating that cancers evolve during progression and therapy $(7,16-19)$. Therapy represents a very defined and stringent selection pressure during the evolution of a cancer, and several studies have now traced the clonal evolution of tumors during the course of treatment $(13,20-24)$. Selective evolution of cancer is likely to have important consequences in clinical practice and novel techniques to obtain representative samples for genetic analyses, especially from metastatic and recurrent disease, are urgently needed to understand the clonal dynamics of evolving tumors through course of disease and therapy.

\section{TUMOR-SITE-BASED HETEROGENEITY OF SOLID TUMOR}

Numerous genomic studies have demonstrated intratumor heterogeneity and heterogeneity in primary tumors, corresponding metastatic and recurrent tumors as recognized characteristics of solid tumors $(9-15,21$, 25-38). These genomic differences may affect the clinical outcome of anticancer therapy. The results of a retrospective study gave us the direct evidence to reveal that the genetic heterogeneity in primary colorectal tumors and their corresponding metastases have different responses to EGFR-targeted therapy (39).
Studies of glioma recurrences found that the driver mutation landscapes were often significantly different from the initially detected driver mutations, suggesting that clones initiating recurrences had branched off early in tumor evolutionary histories (21). Morrissy AS, et al. demonstrated the heterogeneity between primary tumor and recurrent tumor (26). These studies indicated that molecularly targeted therapy is unlikely to be effective when the target is absent in the metastatic or recurrent tumors. In certain contexts, continued therapy in absent of target might accelerate tumor progression (40).

\section{PATIENT-DERIVED TUMOR XENOGRAFT (PDX) MODEL FOR PERSONALIZED AND DYNAMIC THERAPY FOR BREAST CANCER}

The patient-derived tumor xenograft (PDX) model has a sound establishing method and a retained similarity to the corresponding original donor tumors in histologic presentation and biological behavior. The PDX model has the potential to be a candidate strategy for personalized cancer therapy. The results of a study led the investigators to conclude that the PDX model of first generation of non-small cell lung cancer (NSCLC) is suitable for quick assessment of the chemosensitivity of patients' cancers and selection of the most effective regimens. In this study, the first generation subrenal capsule xenografts of primary NSCLC were examined for determining responses to conventional chemotherapeutic regimens and selecting regimens most effective for individual patients (41). In a large preclinical trial, the investigators established 1,075 PDX models from a range of human solid tumor samples and carried out a PDX clinical trial with 62 treatments. Their results correlated genomic alterations with responses to therapy, which confirmed the relationships that have already been established and thus validated the approach (6).

The PDX models of primary and metastatic tumors have been established in our laboratory and have been used for antitumor drug sensitivity assays which could guide clinical practice of personalized cancer therapy $(4,42-48)$. Based on our clinical and laboratorial experience, it is practical to obtain primary or metastatic breast cancer for PDX model use even if the spreading of the tumor is extensive.

\section{NEXT-GENERATION SEQUENCING}

Recent advances in genomics technologies are now providing new opportunities for the analysis of tumor 
DNA. NGS technologies are now being applied to tumor DNA analysis to allow more comprehensive detection of mutations across wider genomic regions. Advances in NGS have made it possible to precisely characterize all somatic coding mutations that occur during the development and progression of individual cancers (10, $11,14,15,26,37,49-54)$. Whole-genome sequencing (WGS) has now been directly applied to tumor DNA analysis, to provide an unprecedented view of somatic chromosomal alterations and copy number aberrations in tumor DNA genome-wide (10,11,14,15,26,37,49-54). NGS of tumor DNA could be an effective tool for monitoring tumor burden, evolution, therapeutic responses and resistance to therapy.

Monitoring tumor burden and treatment response is important in all phases of cancer management to avoid continuing ineffective therapies, to prevent unnecessary side-effects and to determine the benefit of new therapeutics. The technique of NGS facilitated the oncologists to investigate cancer to a new level, the dynamic genetic level.

\section{HYPOTHESIS AND PERSPECTIVE}

Given these advances and the scientific data mentioned above, here we hypothesize and illustrate a proposed preclinical strategy of personalized and dynamic therapy for breast cancer based on the technologies of NGS and PDX model (fig. 1). In this strategy, radical surgery will be firstly performed when a
Figure 1 - A proposed preclinical strategy of personalized and dynamic therapy for breast cancer based on a patient-derived tumor xenograft (PDX) model

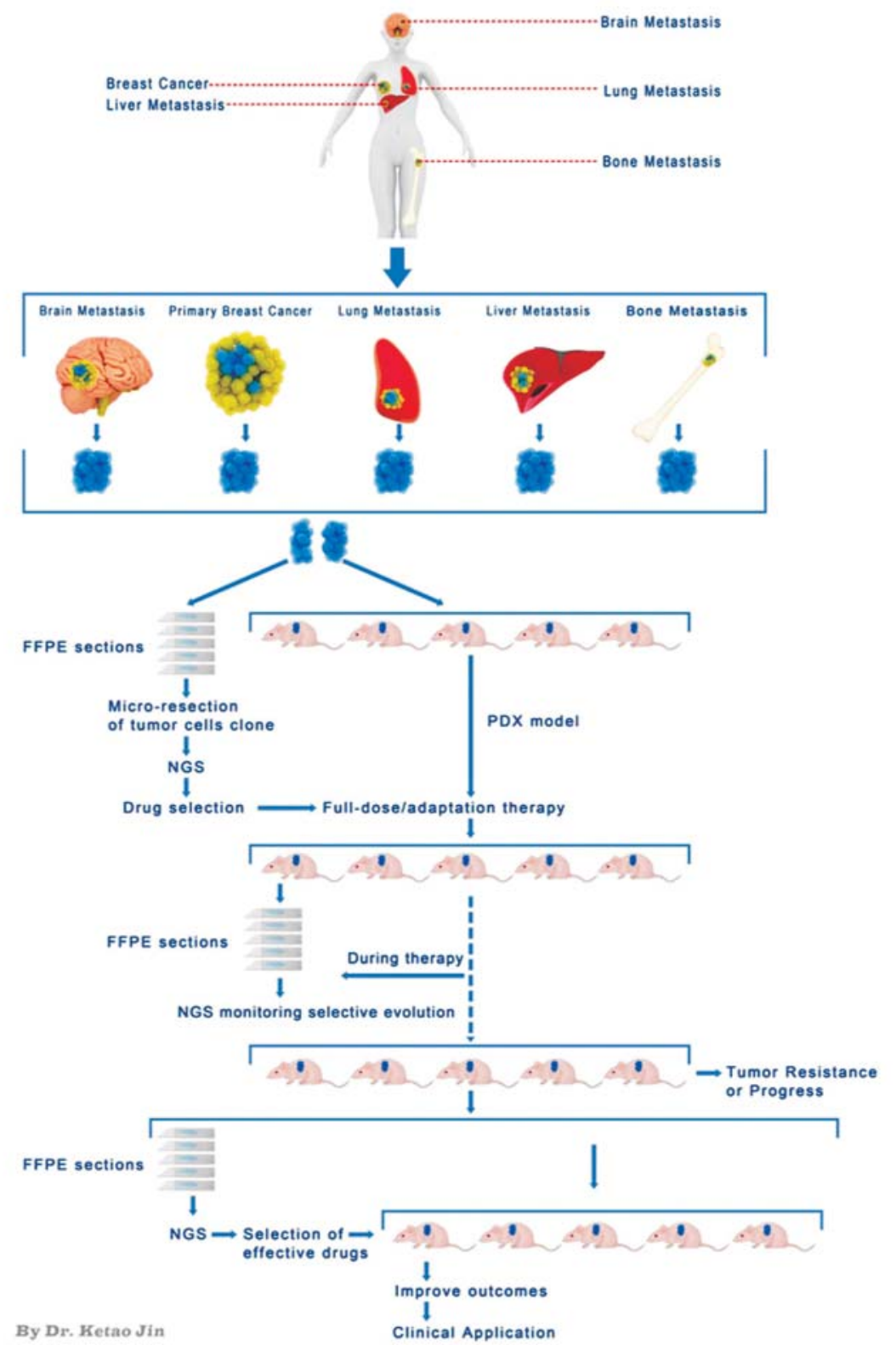


breast cancer is pathologically confirmed, following the dynamic therapy such as chemotherapy or chemotherapy in combination with molecularly targeted therapy based on the results from NGS using tumor DNA and imaging technologies such as CT, MRI or PET-CT. In this process, the tumor DNA from the resection of primary breast tumor and metastatic tumors such as brain metastasis, lung metastasis, and bone metastasis were sent for NGS analysis to obtain the drug sensitivity data for drug selection. And simultaneously, part of resected tumors was used for establishment of PDX model for therapy interference using the same drugs as the patient received. During the generation of PDX, the tumors were resected for monitor the selective evolution of tumor in selected time points to obtain the drug resistance data for termination of the current ineffective therapies and obtain the renewed drug sensitivity data to choose new effective drugs. These renewed drugs sensitivity data from PDX model could be used for drug selection when the metastases or recurrence of breast cancer occurred. The goal of this proposed preclinical strategy is to realize personalized and dynamic systemic therapy for cancer and improve patients' outcomes.

\section{Disclosure of conflict of interest}

None.

\section{Acknowledgments}

This work was supported by National Natural Science Foundation of China (Grant No. 81374014), Zhejiang Provincial Science and Technology Projects (grants no. 2015C33264, 2017C33212 and 2017C33213), and Zhejiang Provincial Medical and Healthy Science and Technology Projects (Grants No. 2013KYA228 and 2016KYA180).

\section{REFERENCES}

1. Torre LA, Bray F, Siegel RL, Ferlay J, Lortet-Tieulent J, Jemal A. Global cancer statistics, 2012. CA Cancer J Clin. 2015 Mar;65(2):87-108. doi: 10.3322/caac.21262. Epub 2015 Feb 4.

2. Chen W, Zheng R, Baade PD, Zhang S, Zeng H, Bray F, et al. Cancer statistics in China, 2015. CA Cancer J Clin. 2016 Mar-Apr;66(2):11532. doi: 10.3322/caac.21338. Epub 2016 Jan 25.

3. Huynh H, Soo KC, Chow PK, Panasci L, Tran E. Xenografts of human hepatocellular carcinoma: a useful model for testing drugs. Clin Cancer Res. 2006 Jul 15;12(14 Pt 1):4306-14.

4. Jin K, Li G, Cui B, Zhang J, Lan H, Han N, et al. Assessment of a novel VEGF targeted agent using patient-derived tumor tissue xenograft models of colon carcinoma with lymphatic and hepatic metastases. PLoS One. 2011;6(12):e28384. doi: 10.1371/journal.pone.0028384. Epub 2011 Dec 2.

5. Hammer S, Sommer A, Fichtner I, Becker M, Rolff J, Merk J, et al. Comparative profiling of the novel epothilone, sagopilone, in xenografts derived from primary non-small cell lung cancer. Clin Cancer Res. 2010 Mar 1;16(5):1452-65. doi: 10.1158/1078-
0432.CCR-09-2455. Epub 2010 Feb 23.

6. Gao H, Korn JM, Ferretti S, Monahan JE, Wang Y, Singh M, et al. Highthroughput screening using patient-derived tumor xenografts to predict clinical trial drug response. Nat Med. 2015 Nov;21(11):131825. doi: 10.1038/nm.3954. Epub 2015 Oct 19.

7. Yates LR, Campbell PJ. Evolution of the cancer genome. Nat Rev Genet. 2012 Nov;13(11):795-806. doi: 10.1038/nrg3317. Epub 2012 Oct 9.

8. Aparicio S, Caldas C. The implications of clonal genome evolution for cancer medicine. N Engl J Med. 2013 Feb 28;368(9):842-51. doi: 10.1056/NEJMra1204892.

9. Diaz LA Jr, Williams RT, Wu J, Kinde I, Hecht JR, Berlin J, et al. The molecular evolution of acquired resistance to targeted EGFR blockade in colorectal cancers. Nature. 2012 Jun 28;486(7404):537-40. doi: 10.1038/nature11219.

10. Shah SP, Roth A, Goya R, Oloumi A, Ha G, Zhao Y, et al. The clonal and mutational evolution spectrum of primary triple-negative breast cancers. Nature. 2012 Apr 4;486(7403):395-9. doi: 10.1038/ nature10933.

11. Gerlinger M, Rowan AJ, Horswell S, Larkin J, Endesfelder D, Gronroos $\mathrm{E}$, et al. Intratumor heterogeneity and branched evolution revealed by multiregion sequencing. N Engl J Med. 2012 Mar 8;366(10):883-92. doi: 10.1056/NEJMoa1113205. Erratum in N Engl J Med. 2012 Sep 6:367(10):976.

12. Campbell PJ, Yachida S, Mudie LJ, Stephens PJ, Pleasance ED, Stebbings LA, et al. The patterns and dynamics of genomic instability in metastatic pancreatic cancer. Nature. 2010 0ct 28;467(7319):110913. doi: 10.1038/nature09460.

13. Bashashati A, Ha G, Tone A, Ding J, Prentice LM, Roth A, et al. Distinct evolutionary trajectories of primary high-grade serous ovarian cancers revealed through spatial mutational profiling. J Pathol. 2013 Sep; 231(1):21-34. doi: 10.1002/path.4230.

14. de Bruin EC, McGranahan N, Mitter R, Salm M, Wedge DC, Yates L, et al. Spatial and temporal diversity in genomic instability processes defines lung cancer evolution. Science. 2014 0ct 10;346(6206):2516. doi: 10.1126/science.1253462.

15. Zhang J, Fujimoto J, Zhang J, Wedge DC, Song X, Zhang J, et al. Intratumor heterogeneity in localized lung adenocarcinomas delineated by multiregion sequencing. Science. 2014 Oct 10;346(6206):256-9. doi: 10.1126/science.1256930.

16. Greaves M, Maley CC. Clonal evolution in cancer. Nature. 2012 Jan 18;481(7381):306-13. doi: 10.1038/nature10762.

17. Misale S, Yaeger R, Hobor S, Scala E, Janakiraman M, Liska D, et al. Emergence of KRAS mutations and acquired resistance to anti-EGFR therapy in colorectal cancer. Nature. 2012 Jun 28;486(7404):532-6. doi: 10.1038/nature11156.

18. Juric $\mathrm{D}$, Castel $\mathrm{P}$, Griffith $\mathrm{M}$, Griffith $\mathrm{OL}$, Won $\mathrm{HH}$, Ellis $\mathrm{H}$, et al. Convergent loss of PTEN leads to clinical resistance to a $\mathrm{PI}(3) \mathrm{Ka}$ inhibitor. Nature. 2015 Feb 12;518(7538):240-4. doi: 10.1038/ nature13948. Epub 2014 Nov 17.

19. Engelman JA, Zejnullahu K, Mitsudomi T, Song Y, Hyland C, Park JO, et al. MET amplification leads to gefitinib resistance in lung cancer by activating ERBB3 signaling. Science. 2007 May 18;316(5827):103943. Epub 2007 Apr 26.

20. Castellarin M, Milne K, Zeng T, Tse K, Mayo M, Zhao Y, et al. Clonal evolution of high-grade serous ovarian carcinoma from primary to recurrent disease. J Pathol. 2013 Mar;229(4):515-24. doi: 10.1002/ path.4105. Epub 2012 Nov 29.

21. Johnson BE, Mazor T, Hong C, Barnes M, Aihara K, McLean CY, et al. Mutational analysis reveals the origin and therapy-driven evolution of recurrent glioma. Science. 2014 Jan 10;343(6167):189-93. doi: 10.1126/science.1239947. Epub 2013 Dec 12.

22. Shi H, Hugo W, Kong X, Hong A, Koya RC, Moriceau G, et al. Acquired resistance and clonal evolution in melanoma during BRAF inhibitor therapy. Cancer Discov. 2014 Jan;4(1):80-93. doi: 10.1158/21598290.CD-13-0642. Epub 2013 Nov 21.

23. Siravegna $G$, Mussolin B, Buscarino M, Corti G, Cassingena A, Crisafulli G, et al. Clonal evolution and resistance to EGFR blockade in the blood of colorectal cancer patients. Nat Med. 2015 Jul;21(7):795801. doi: 10.1038/nm.3870. Epub 2015 Jun 1.

24. Misale S, Di Nicolantonio F, Sartore-Bianchi A, Siena S, Bardelli A. 
Resistance to anti-EGFR therapy in colorectal cancer: from heterogeneity to convergent evolution. Cancer Discov. 2014 Nov;4(11): 1269-80. doi: 10.1158/2159-8290.CD-14-0462. Epub 2014 0ct 7.

25. Scartozzi M, Bearzi I, Berardi R, Mandolesi A, Fabris G, Cascinu S Epidermal growth factor receptor (EGFR) status in primary colorectal tumors does not correlate with EGFR expression in related metastatic sites: implications for treatment with EGFR-targeted monoclonal antibodies. J Clin Oncol. 2004 Dec 1;22(23):4772-8.

26. Morrissy AS, Garzia L, Shih DJ, Zuyderduyn S, Huang X, Skowron P, et al. Divergent clonal selection dominates medulloblastoma at recurrence. Nature. 2016 Jan 21;529(7586):351-7. doi: 10.1038/ nature16478. Epub 2016 Jan 13.

27. Burrell RA1, McGranahan N, Bartek J, Swanton C. The causes and consequences of genetic heterogeneity in cancer evolution. Nature. 2013 Sep 19;501(7467):338-45. doi: 10.1038/nature12625.

28. Lawrence MS, Stojanov P, Mermel CH, Robinson JT, Garraway LA, Golub TR, et al. Discovery and saturation analysis of cancer genes across 21 tumour types. Nature. 2014 Jan 23;505(7484):495-501. doi: 10.1038/nature12912. Epub 2014 Jan 5.

29. Lawrence MS, Stojanov P, Polak P, Kryukov GV, Cibulskis K, Sivachenko A, et al. Mutational heterogeneity in cancer and the search for new cancer-associated genes. Nature. 2013 Jul 11;499(7457):2148. doi: 10.1038/nature12213. Epub 2013 Jun 16.

30. Kandoth C, McLellan MD, Vandin F, Ye K, Niu B, Lu C, et al. Mutational landscape and significance across 12 major cancer types. Nature. 2013 Oct 17;502(7471):333-9. doi: 10.1038/nature12634.

31. Alexandrov LB, Nik-Zainal S, Wedge DC, Aparicio SA, Behjati S, Biankin AV, et al. Signatures of mutational processes in human cancer. Nature. 2013 Aug 22;500(7463):415-21. doi: 10.1038/nature12477. Epub 2013 Aug 14.

32. Nik-Zainal S, Van Loo P, Wedge DC, Alexandrov LB, Greenman CD, Lau KW, et al. The life history of 21 breast cancers. Cell. 2012 May 25;149(5):994-1007. doi: 10.1016/..cell.2012.04.023. Epub 2012 May 17.

33. Navin N, Kendall J, Troge J, Andrews P, Rodgers L, Mclndoo J, et al. Tumour evolution inferred by single-cell sequencing. Nature. $2011 \mathrm{Apr}$ 7:472(7341):90-4. doi: 10.1038/nature09807. Epub 2011 Mar 13.

34. Yachida S, Jones S, Bozic I, Antal T, Leary R, Fu B, et al. Distant metastasis occurs late during the genetic evolution of pancreatic cancer. Nature. 2010 Oct 28;467(7319):1114-7. doi: 10.1038/nature09515.

35. Gerlinger M, Horswell S, Larkin J, Rowan AJ, Salm MP, Varela I, et al Genomic architecture and evolution of clear cell renal cell carcinomas defined by multiregion sequencing. Nat Genet. 2014 Mar;46(3):22533. doi: 10.1038/ng.2891. Epub 2014 Feb 2.

36. Sottoriva A, Spiteri I, Piccirillo SG, Touloumis A, Collins VP, Marioni JC, et al. Intratumor heterogeneity in human glioblastoma reflects cancer evolutionary dynamics. Proc Natl Acad Sci U S A. 2013 Mar 5;110(10):4009-14. doi: 10.1073/pnas.1219747110. Epub 2013 Feb 14.

37. Carreira S, Romanel A, Goodall J, Grist E, Ferraldeschi R, Miranda S, et al. Tumor clone dynamics in lethal prostate cancer. Sci Transl Med. 2014 Sep 17;6(254):254ra125. doi: 10.1126/scitransImed.3009448.

38. Haffner MC, Mosbruger T, Esopi DM, Fedor H, Heaphy CM, Walker DA et al. Tracking the clonal origin of lethal prostate cancer. J Clin Invest. 2013 Nov;123(11):4918-22. doi: 10.1172/JCI70354. Epub 2013 Oct 25.

39. Loupakis F, Pollina L, Stasi I, Ruzzo A, Scartozzi M, Santini D, et al PTEN expression and KRAS mutations on primary tumors and metastases in the prediction of benefit from cetuximab plus irinotecan for patients with metastatic colorectal cancer. J Clin Oncol. 2009 Jun 1:27(16):2622-9. doi: 10.1200/JC0.2008.20.2796. Epub 2009 Apr 27.

40. Lohr JG, Stojanov P, Carter SL, Cruz-Gordillo P, Lawrence MS, Auclair
D, et al. Widespread genetic heterogeneity in multiple myeloma: implications for targeted therapy. Cancer Cell. 2014 Jan 13;25(1):91101. doi: 10.1016/j.ccr.2013.12.015.

41. Dong X, Guan J, English JC, Flint J, Yee J, Evans K, et al. Patientderived first generation xenografts of non-small cell lung cancers: promising tools for predicting drug responses for personalized chemotherapy. Clin Cancer Res. 2010 Mar 1;16(5):1442-51. doi: 10.1158/1078-0432.CCR-09-2878. Epub 2010 Feb 23.

42. Jin K, Teng L, Shen Y, He K, Xu Z, Li G. Patient-derived human tumour tissue xenografts in immunodeficient mice: a systematic review. Clin Transl Oncol. 2010 Jul;12(7):473-80. doi: 10.1007/s12094-010-05406

43. Jin K, He K, Han N, Li G, Wang H, Xu Z, et al. Establishment of a PDTT xenograft model of gastric carcinoma and its application in personalized therapeutic regimen selection. Hepatogastroenterology. 2011 Sep-0ct;58(110-111):1814-22. doi: 10.5754/hge11136. Epub 2011 Jul 15.

44. Jin K, Lan H, Cao F, Xu Z, Han N, Li G, et al. Antitumor effect of FP3 in a patient-derived tumor tissue xenograft model of gastric carcinoma through an antiangiogenic mechanism. Oncol Lett. 2012 May;3(5): 1052-1058. Epub 2012 Feb 10

45. Jin K, Lan H, Xie B, He K, Xu Z, Li G, et al. Antitumor effects of FP3 in combination with capecitabine on PDTT xenograft models of primary colon carcinoma and related lymphatic and hepatic metastases. Cancer Biol Ther. 2012 Jul;13(9):737-44. Epub 2012 May 23.

46. Jin K, Lan H, Cao F, Han N, Xu Z, Li G, et al. Differential response to EGFR- and VEGF-targeted therapies in patient-derived tumor tissue xenograft models of colon carcinoma and related metastases. Int $\mathrm{J}$ Oncol. 2012 Aug;41(2):583-8. doi: 10.3892/ijo.2012.1469. Epub 2012 May 10.

47. Dong X, Jin K, Hu X, Du F, Lan H, Han N, et al. Antitumor effect of FP3 in combination with cetuximab on patient-derived tumor tissue xenograft models of primary colon carcinoma and related lymphatic and hepatic metastases. Int J Mol Med. 2012 Jul;30(1):126-32. doi: 10.3892/ijmm.2012.968. Epub 2012 Apr 10.

48. Pan W, Huang S, Zhang J, Zhao B, Wang H, Liu F, et al. Heterogeneityrelated anticancer therapy response differences in metastatic colon carcinoma: new hints to tumor-site-based personalized cancer therapy. Hepatogastroenterology. 2013 Nov-Dec;60(128):1927-34.

49. Naxerova K, Jain RK. Using tumour phylogenetics to identify the roots of metastasis in humans. Nat Rev Clin Oncol. 2015 May;12(5):258-72. doi: 10.1038/nrclinonc.2014.238. Epub 2015 Jan 20.

50. Cristescu R, Lee J, Nebozhyn M, Kim KM, Ting JC, Wong SS, et al. Molecular analysis of gastric cancer identifies subtypes associated with distinct clinical outcomes. Nat Med. 2015 May;21(5):449-56. doi: 10.1038/nm.3850. Epub 2015 Apr 20.

51. Bhang HE, Ruddy DA, Krishnamurthy Radhakrishna V, Caushi JX, Zhao R, Hims MM, et al. Studying clonal dynamics in response to cancer therapy using high-complexity barcoding. Nat Med. 2015 May:21(5):440-8. doi: 10.1038/nm.3841. Epub 2015 Apr 13.

52. Eirew P, Steif A, Khattra J, Ha G, Yap D, Farahani H, et al. Dynamics of genomic clones in breast cancer patient xenografts at single-cell resolution. Nature. 2015 Feb 19;518(7539):422-6. doi: 10.1038/ nature13952. Epub 2014 Nov 26.

53. Ding L, Ley TJ, Larson DE, Miller CA, Koboldt DC, Welch JS, et al. Clonal evolution in relapsed acute myeloid leukaemia revealed by whole-genome sequencing. Nature. 2012 Jan 11;481(7382):506-10. doi: 10.1038/nature10738.

54. Gundem G, Van Loo P, Kremeyer B, Alexandrov LB, Tubio JM, Papaemmanuil $E$, et al. The evolutionary history of lethal metastatic prostate cancer. Nature. 2015 Apr 16;520(7547):353-7. doi: 10.1038/ nature14347. Epub 2015 Apr 1. 